\title{
Optimising Student Learning Outcomes: For Agricultural Management at the University of South Africa
}

\author{
Mosima Makola \\ Regional Academic Coordinator, University of South Africa \\ mmakola@unisa.ac.za
}

\section{Doi:10.5901/mjss.2014.v5n27p807}

\begin{abstract}
This paper presents a model for Work Integrated Learning (WIL) where academics, monitors and mentors collaborate to provide the learning experiences for students. At its core, the model features facilitated mentoring and reflective practices based on experiential learning theory. The students find themselves in the world of the Work Integrated learning experience which provides the physical context for learning. Mentors collaborate with monitors and students to design a learning plan and to facilitate the reflective processes. The paper will discuss the interactions that are supported through the process of facilitated mentoring and reflective learning practices where the challenge was to ensure that learning did occur and to be able to demonstrate that it occurred.
\end{abstract}

Keywords: Work Integrated Learning, optimisation, reflections, collaboration, learning outcomes

\section{Introduction}

Work Integrated Learning, with specific reference to achieving learning outcomes, has become a crucial part of practice at the University of South Africa (Unisa). In 2003 the Department of Education began with the process of merging some institutions of higher learning, in order to serve the interests of students. This arrangement will continue to present some challenges to newly formed comprehensive universities in the foreseeable future. It is becoming essential for staff of comprehensive universities to adapt to this change and embrace Work Integrated Learning (WIL) developments. The advancement of WIL has a substantial impact on Unisa activities in that this service will have to be quality assured. The adoption of quality assurance through mentoring, monitoring and continuous assessment will improve learning outcomes, diversify the learning strategies and achieve international competitiveness. In order for WIL to be successful, it has to be quality assured. It is therefore imperative to determine the strategic roles that contribute to the process of optimising the learning outcomes of the WIL students. An understanding of stakeholders' roles is essential.

This paper will therefore present an overview of optimising learning outcomes of students during workplace learning in agricultural management. In that way it will also serve as a context for the study.

On the one hand, according to a previous pilot study report on monitoring at Unisa (i.e. pilot study on monitoring of WIL for three qualifications amongst which Agricultural Management formed part) some monitors could not differentiate their roles. They did not know the difference between being a monitor and being a mentor. A mentor is someone who provides expertise to less experienced individuals to help them advance their careers, enhance their education and build their networks. A monitor is someone who is supervising activities in progress to ensure they are on-course and onschedule in meeting the objectives and performance targets. On the other hand, some students could not reflect much on what they have learnt during their placement. In his report, Groenewald (2009) indicated that one monitor considered himself as a mentor as well. It is against this background that the learning outcomes of agricultural management needed to be evaluated by the author. The author holds the view that WIL students should be able to reflect on what they have learnt in order for all stakeholders to be convinced that indeed learning has taken place.

This study provides the perspective on learning outcomes, expanding on the work done by the Groenewald (2009) on the monitoring project. This study will serve to inform the University about the impact of piloting monitoring, using students as participants. As far as the author is concerned, the impact of WIL monitoring has not yet been assessed.

This research will broaden the knowledge base and the understanding of the optimisation of the learning outcome by focusing on the strategies and roles to be played by each stakeholder within WIL. The research study attempted to highlight involvement of students, together with their mentors, in an empirical basis for understanding the adoption of mentoring plans. 


\section{Contextual Framework and Related Literature}

Kolb (1984) created his famous model of experiential learning out of four elements: concrete experience, observation and reflection, the formation of abstract concepts and testing in new situations. He represented these in the famous experiential learning circle that involves (1) concrete experience (which he believes is a state where a learner is on his/her new experience); followed by (2) reflective observation and experience (where a learner learns by watching others or develop observations about one's own experience); then followed by (3) forming abstract concepts (where a learner is creating theories to explain observation), lastly followed by (4) testing in new situations, which he called "active experimentation" (a stage where a learner should use theory to solve problems and make decisions). It is a famous model that is found in many discussions of the theory and practice of adult education, informal education and lifelong learning. Like many other theorists, Kolb (1984) believes learning is based on how we think about things and how we approach things. He further states that reflective observation engages learners in the activities that will require them to step back and look at the experience and/or obtain the perspectives of other people

Rodney \& Horsley [2011] did, however, critique Kolb's theory. They differentiated experiential learning from discovery learning. These authors are of opinion that activities must be carefully designed by teachers and learners must reflect on their experiences in a critical way. On the other hand, Houle (1980: 221) explains experiential learning as 'education that occurs as a direct participation in the events of life'. It is learning that is achieved through reflection upon everyday experience and is the way that most of us do our learning.

Gumbo (2006) argued that knowledge, skills and attitudes can only be acquired at the place of work where all young people should learn about the way business operates, employers' and employees' roles, and rules and responsibilities in the real world of work.

Kruse et al (2012) used games in their experiential learning model. They primarily used questions with the intention to make the most out of a situation. They then expected learners to reflect on the activity. Several questions would be asked on the observations one had made from the game. The types of questions asked were: What happened in the activity? or What were the results? Everyone in the group was then expected to share their own observations on what was going on. Listening to all observations was important, as the principle that everyone deserves a chance to talk was applied. Questions could be extended to What was the most difficult part of this activity? and what their gut reaction was. If someone was left out, how did they feel being left out? How did it feel to lead? What problems or issues seemed to occur over and over? How did you feel when a particular thing happened? In this way, each learner was forced to reflect and participate.

Schon (1978), like other theorists, made a remarkable contribution to the development of reflective practice and learning systems within various organisations and communities. He pioneered the idea of single-loop and double-loop learning. Schon (1978) explains single-loop learning as the continuation of the practitioner's reliance on the current strategy despite the error or fault experienced. He further explains that a practitioner continues with techniques or policies when the situation comes back to light. Schon (1978) describes double-loop learning as the situation where modification of personal objectives, strategies or policies is done and a new framework is applied when a new situation starts.

Schon (1978) has also introduced concepts or "reflection-in-action" and "reflection-on-action". He explains "reflection-in-action" as the ability of a practitioner to "think on his feet" when faced with issues. A practitioner should connect with his/her feelings, emotions and prior experience to attend to the challenge directly. "Reflection-on-action", on the other hand, is the idea that after the experience, a practitioner analyses his/her reaction to the challenge and explores the possible reasons around such challenge

WIL should have great academic significance. It must be meaningful, valuable and relevant to what students learn in their study material, prior to going out and after they return from work placement. For students to benefit maximally all stakeholders should work together purposefully and there has to be a better coordination of efforts. In all these, students' goals should be at the centre of everything.

It is becoming essential for staff of comprehensive universities to adapt to change and embrace WIL developments. The adoption of quality assurance through mentoring, monitoring and continuous assessment will improve learning outcomes, diversify the learning strategies and achieve international competitiveness. Given the importance of staff acceptance and adoption of quality assurance, it is imperative to determine the strategic roles that contribute to the process of optimising learning outcomes of the students. An understanding of roles of all the stakeholders is essential.

\section{Research Methodology}

This study was based on action research methodology where all participants were jointly involved in the project. Welman 
(2001) explained action research as a research methodology which is conducted with a view to find a solution for a particular practical problem situation in a specific applied setting. The purpose of this paper was not to develop a theory, but rather to find a solution to WIL situations. The idea was to come up with a practical model that would assist learners to develop reflective learning tactics and optimise their learning outcomes. According to Hart and Bond (1995), action research can be used as a tool to focus on problems and challenges experienced and focus on future plans.

\subsection{Pilot study on monitoring the Work Integrated Learning}

Monitoring of WIL is emphasised by the Department of Education and Higher Education Quality Committee (HEQC) as being imperative. Following this recommendation, Unisa undertook a pilot project during the last quarter of 2008 on monitoring three qualifications with a WIL component. Those qualifications are Animal Health, Chemical Engineering and Agricultural Management. For the purpose of this study the focus was on Agricultural Management. The purpose was to explore, with reference to the learning outcomes, the actual learning students acquired. The overriding question in this study was: Did learning occur and are students able to demonstrate that it occurred in order to derive or optimise the relevant learning significance?

\subsection{Report on the pilot project to monitor the Work Integrated Learning by Groenewald (2009) on the part of agricultural management}

The intention of Groenewald's (2009) project was to monitor all students registered for the following modules: Agricultural Production Management II (GPM201A), Agricultural Production Techniques II (AGT201A) and Agricultural Practice III (AGP301A) - the three Work Integrated Learning modules in 2008, but the purpose was not accomplished. The report contained no concrete indication of the progress of students. Out of 13 monitors only five could do the actual monitoring. Others could not be utilised because students were not placed. Only 29 students were monitored.

\subsection{Summary of students' and monitors' responses:}

\subsubsection{Students' responses}

- $61 \%$ of the respondents agreed that they are satisfied with the orientation and process of Work Integrated Learning at Unisa

- $56 \%$ of the respondents agreed that they received additional training other than the Unisa requirements.

- $53 \%$ of the respondents did not have a specific supervisor/mentor at their current companies.

- $52 \%$ of the respondents were satisfied with their supervisors or mentors.

\subsubsection{Mentors' responses}

- $48 \%$ of the respondents agreed that they had clarity of what was expected of them by Unisa.

- $42 \%$ of the respondents received supervisors' guides from the students.

- $50 \%$ of the respondents were satisfied with the service/contact from the regional Unisa offices.

- $50 \%$ of the respondents were satisfied with the service/contact from the School of Agricultural \& Life Sciences at Unisa.

- $42 \%$ of the respondents were satisfied with the Unisa student(s) undergoing experiential learning.

\subsubsection{Monitors}

- Monitors not knowing their roles, performed several roles in the monitoring process. One monitor, instead of reporting and reflecting on the actual monitoring of the students, assigned himself as the mentor of several students. He also did a good job by arranging with managers at the workplace to allow students more practical exposure.

- One monitor recommended that a database of relevant/suitable hosts should be provided to students, as most of them are not placed.

- Several monitors expressed a lack of communication between stakeholders at Unisa. 
- Another monitor said that students are not sure what is expected of them.

- One monitor said students are uncertain as to how many projects or reports they should send to Unisa for evaluation.

- Frequent contact with students was recommended by monitors.

\subsection{Success stories}

- Students and monitors experienced the monitoring visits as constructive and fruitful.

\subsection{Frustrations}

- One student indicated a frustration of having registered and paid for the module which has never taken place.

- One student had trouble getting along with the mentor.

\subsection{Follow-up report on pilot study}

The purpose of the follow-up study was to establish if learning did occur and to be able to demonstrate that it occurred. This is the main focus of this paper.

\subsubsection{Did learning occur?}

Of the 29 students of Agricultural Management who were placed and monitored by five monitors, only ten could be traced and be interviewed telephonically. The purpose was to establish the experiences each individual student had during placement. From their responses one would agree that learning occurred depending on an individual's interpretation. Students worked on different farms, which is the suitable place for this qualification.

\subsubsection{Can students demonstrate that learning occurred?}

As the aim was to establish if students would be able to explain what happened during Work Integrated Learning, the following responses were generated:

- $40 \%$ seem to have covered all the learning areas.

- $30 \%$ seem to have covered some of the learning areas.

- $10 \%$ were too general about what happened.

- $10 \%$ could not reflect on what happened.

\subsubsection{Student-mentor meetings}

- $10 \%$ had daily sessions.

- $40 \%$ had weekly sessions.

- $30 \%$ had monthly sessions.

- $10 \%$ had bimonthly sessions.

\subsubsection{Record keeping}

- All students kept written records of what they have learnt and only one student mentioned having taken photos.

\subsubsection{Portfolios compiled}

- $70 \%$ compiled portfolios.

- $30 \%$ not yet compiled. 


\subsubsection{Training plans}

Students were not clear on how they would prefer training plans. One student preferred training to take place on quarterly intervals to accommodate all the working students. Another student said the learning materials should indicate the important topics to be covered instead of being told at the end of training/placement that some topics were unnecessary.

\section{Management of Work Integrated Learning placement}

Cooper, Bottomley and Gordon (2004) emphasised the management of the placement learning environment and experiences as an important tool to provide an effective learning experience for students. This should cascade to the management of learning environment during placement and once the placement has finished, it is imperative for the institution to integrate roles and responsibilities of all stakeholders before, during and after WIL placement. The author used the basic target model below, which proposes that the student should be at the centre. All other stakeholders should be there to support the student in order to ensure that learning takes place.

Figure 1: Basic Target Model

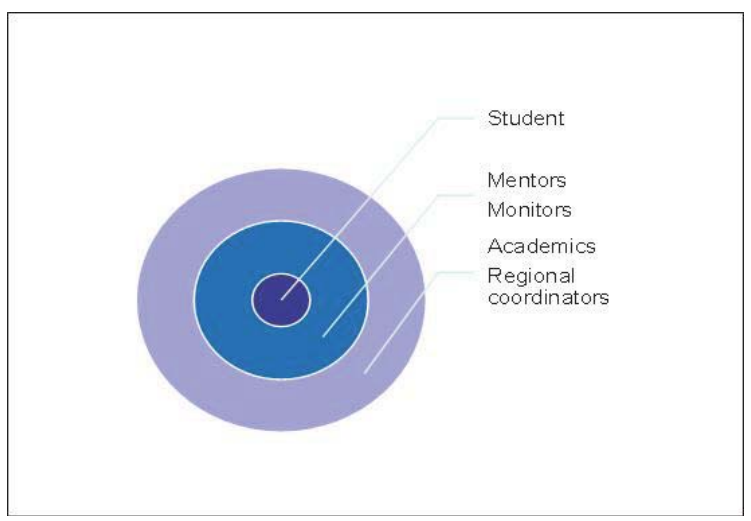

\subsection{Basic target model}

The basic target model illustrates the relationship a student has with mentors, monitors, academics and coordinators. This model is relevant as it shows the student being at the centre of every stakeholder's activities as far as WIL is concerned.

Figure 2: Alternating Flow Model

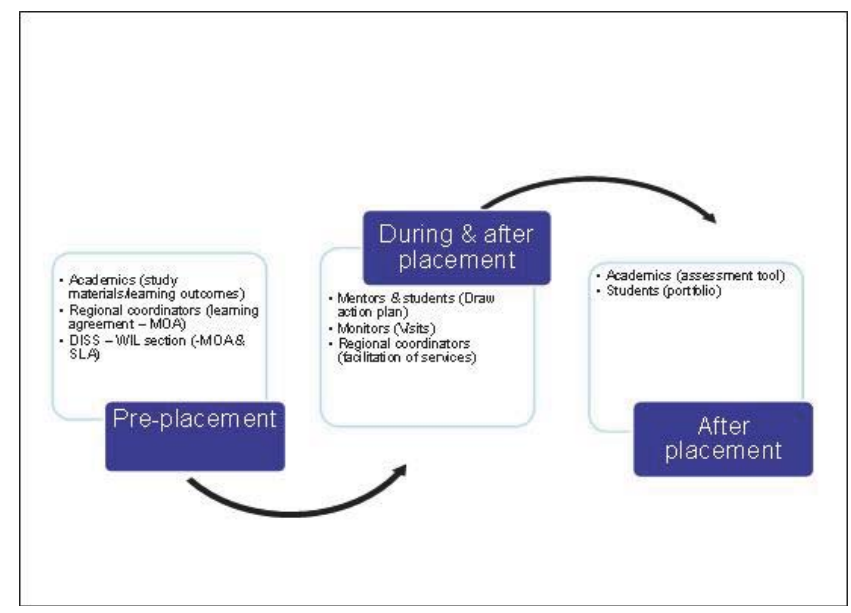




\subsection{Alternating Flow Model}

The model is important as it shows groups of information or sequential steps in the task, process or workflow. It also emphasises the interaction or relationships among the groups of information.

Management of WIL placement integrates roles and responsibilities of all stakeholders before, during and after WIL placement as explained below:

\subsection{Pre-placement}

\subsubsection{Academics/lecturers}

It is the duty of the academics/lecturers, before placement, to develop learning materials/logbooks relevant to the workplace environment. Ideally they should seek advice from industry when doing so to enable effective facilitation of learning. The assessment tool should be clearly communicated to students, mentors, monitors and regional coordinators.

\subsubsection{Regional Academic Coordinators}

Regional Academic Coordinators are Unisa staff members based at regional service centres that are responsible for various learner support programmes, including WIL. These coordinators play a major role in the establishment of partnerships with companies and in the placement of students. There should be continuous communication between academics and Regional Academic Coordinators. Their roles are:

- Facilitation of monitoring visits to workplaces

- Processing monitors' claims

- Serving as communication channel for all stakeholders

\subsubsection{Directorate: Instructional and Support Services (DISS)}

The learning agreements or Memorandum of Agreement (MOA), as compiled by the WIL section of the Directorate: Instructional and Support Services (DISS), should clearly indicate the commitment of each stakeholder involved. The development of knowledge and skills to all parties involved is essential. Based on the Unisa model of learning, there should be a service level agreement (SLA) between academics/educators and regional staff on how to manage the actual placement in order to meet the learning outcomes.

\subsection{Management prior to placement and during placement}

\subsubsection{Mentors and students}

Mentors should have know-how and skills to determine the learning environments. Mentors should assess their strengths and weaknesses and seek advice within their structures in order to improve their performance during placement. They should also consider the external factors in their organisations that will affect their performance during and after placement of students. Mentors should assess the opportunities and use them to maximise learning experiences of students. In the case of threats, they should minimise their impact and develop contingency plans to overcome them.

Mentors should also seek information about the background of students. They should ask the placement coordinators about the available communication mechanism with the institution. They should interview students, in order to determine their learning needs. This could develop and improve the skills and attitudes to learning experiences of students and mentors.

Among others, mentors' roles are:

- Daily/weekly reflective feedback with students

- Guide students on updating their portfolios

- Continuous assessment and review to improve performance and keep the momentum going 


\subsubsection{Monitors}

- Monitors have the role of visiting the workplace to establish the learning progress of students. These visits are vital for ensuring the quality of students' learning experiences. Mentors, as service providers, may also be involved in this process as it will provide them with feedback about the placement they have provided. The visits will help them to reflect on what was intended to happen and what actually happened. They can therefore learn and develop their roles as mentors. A monitor's role is to visit students at the workplace to determine the learning progress. These visits should reflect back on what was intended to happen and what actually happened.

\subsubsection{Regional Academic Coordinator}

- There should be continuous communication between academics and Regional Academic Coordinators.

\subsection{After-placement management}

After-placement academics are vital to implement assessment tool. Student should complete and submit portfolio.

\section{Optimising Learning Outcomes of Students during WIL}

Various stakeholders, directly or indirectly, are concerned about the learning outcomes of students.

- Professional bodies e.g. Agricultural Research Council (ARC) - are concerned about the competencies derived from the work integrated learning programmes

- HEQC is concerned about the quality assurance of WIL placement

- Higher Education Institutions are concerned about the credibility of service providers hosting their students. They are also interested in ensuring that these host organisations begin to instil the sense of professionalism in these students

- Employers need effective workers. When graduates get employed, including Unisa graduates, employers expect them to be productive from the onset. There is no much time available for training as productivity is the employers' main goal.

- Department of labour and workforce development planners are concerned about scaling down striving to reduce the professional and technical skills shortage in the country.

- Students themselves are looking forward to having a successful career that is related to their field of study. In that way, they also aim to earn a salary that relates to their acquired skills.

\section{2009 Student Placement at Agricultural Research Council (ARC)}

To overcome the challenges experienced in the 2008 pilot study, questionnaires were randomly distributed to a group of students placed at the Agricultural Research Council (small stock section). The purpose was to determine if students can demonstrate what they have learnt - their experiences and recommendations on managed placement. The focus was also discussed with the mentor with a purpose of drawing a model that would put everything in perspective to optimise students' learning outcomes.

The outcome demonstrated that students can reflect on what they have learnt.

\subsection{Positive experiences}

- Taking good care of animals

- Using milking machines

- Doing artificial insemination

- Taking blood samples from animals

- Taking animals to the hospital pan when sick

- Injecting and providing medicine to sick animals

- Collecting semen 
- Animal health and nutrition

- Doing a compost or manure by mixing animal excretion and lucerne

- Catching an animal

Students also mentioned to development in the following areas:

- Communication skills

- Time management

- Team work

- Listening skills

- Dedication and passion towards their work

\subsection{Students made the following recommendations}

- Implementation of lecturing sessions

- Establishment of a set of rules

- Involvement in different projects

- Exposure to other divisions at ARC

- Accommodating other aspects in the logbooks

- Exposure to other animals such as cattle and poultry

- Focusing on what the learning outcomes from the logbooks says

- Exposure to dairy the section

- More interaction with the mentor

\subsection{Mentors' comments about the placements are as follows}

Students must be initiative

- They should come up with plans on what they want to learn

- They should be committed, especially with regard to time management

- They should learn to be independent and do things on their own

- Learning outcomes should be revised as some of them cannot be implemented because of their specialist nature

\section{Summary}

The model for optimising learning outcomes of agricultural management students may be incorporated within WIL. This would offer innovative methods of learning in the workplace. These methods can play a role in enhancing the quality of WIL and increase the participation rate and involvement of students. By incorporating students' participation in the mentoring plans, universities and service providers will be able to optimise the learning outcomes of students in agricultural management and offer quality and flexibility in the learning environment.

As the mentor performs certain duties the student watches and in that way learning takes place, directly or indirectly. The model below (i.e. figure 3) explains the interaction of stakeholders where they work like a gear which interlocks as one part. The interaction is like a windmill which will move the whole unit as the wind blows. According to this model, mentors and students should decide on the action plans and draw timetables that are flexible to allow optimised learning outcomes. The gear model below illustrates the action. 


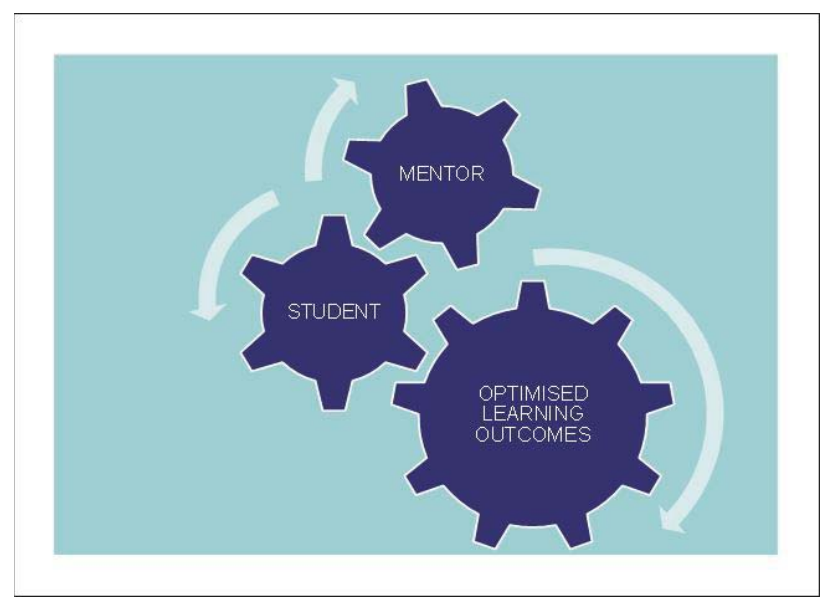

Figure 3: The gear model

\section{Conclusion}

The study examined students' learning outcomes in the Agricultural Management qualification at Unisa It also focused on how to optimise these learning outcomes. The exercise was done to evaluate if learning occurred during Work Integrated Learning. Students were to reflect on their experiences in order to see if what was done was in line with the theoretical information contained in their study materials. Experiences of mentors and monitors were also considered. Based on responses received from all stakeholders a gap was realised. The study suggests the need for collaboration among stakeholders as a tool to improve student learning outcomes. Target and alternative models were explained as a tool to drive the process. Through the stakeholders' interactions, demonstrated by the gear model, students would be able to learn and to demonstrate that learning occurred, thus optimising their learning outcomes.

\section{Bibliography}

Cooper, S, Bottomley, C \& Gordon, J. 2004. Stepping out of classroom and up the ladder of learning: An experiential learning approach to entrepreneurship education. Industry and Higher Education 18(1): 11-22(12).

Groenewald, T. 2009. Lessons derived from a work-integrated learning monitoring pilot at a distance higher education institution. Available at: http://uir.unisa.ac.za/handle/10500/492 (accessed on 12/09/2011).

Gumbo, SD. 2006. A situational analysis of critical factors that influence work related learning quality processes. A case of Midlands State University in Zimbabwe. SASCE International Conference paper 2006.

Hart, E \& Bond, B. 1995. Action research for health and social care: A guide to practice. Buckingham and Philadelphia: Open University Press.

Heerde, J \& Murphy, B. 2009. Work Integrated Learning: An annotated bibliography.

Houle, C. 1980. Continuing Learning in the Professions. San Francisco: Jossey-Bass.

Kolb, DA. 1984. David Kolb's learning styles model and experiential learning theory (ELT). Available at: http:/lwww.businessballs.com/ kolblearningstyles.htm (accessed on 12/09/2011).

Kolb, DA. 1984. Experiential learning: experience as the source of learning and development. Englewood Cliffs, NJ: Prentice Hall.

Kolb, DA \& Fry, R. 1975. Toward an applied theory of experiential learning, in Theories of Group Process, edited by C Cooper. London: John Wiley.

Kruse J, et al (2012) How to use the experiential learning models: 3 steps (www.wikihow.com)

Rodney, D \& Horsley, S. [Sa]. Experiential Learning and Reflection - BA: Teaching and Learning Module. Available at: http://www. slideshare.net/sarahhorsley/experiential- learning-reflection (accessed on 12/09/2011).

Schon, D. 1978. Learning, reflection and change. Available at: http://www.infed.org/thinkers/et-schon.htm (accessed on 12/09/2011).

Welman, CW. 2001. Research methodology for the business and administrative sciences (2nd ed). Cape Town: Oxford University Press. 